\title{
RECONNAISSANCE STUDIES OF POTENTIAL PETROLEUM SOURCE ROCKS IN THE MIDDLE JURASSIC TUXEDNI GROUP NEAR RED GLACIER, EASTERN SLOPE OF ILIAMNA VOLCANO
}

by

Richard G. Stanley ${ }^{1,}$ Trystan M. Herriott ${ }^{2}$, David L. LePain ${ }^{2}$, Kenneth P. Helmold ${ }^{3}$, and C. Shaun Peterson ${ }^{3}$

Previous geological and organic geochemical studies have concluded that organic-rich marine shale in the Middle Jurassic Tuxedni Group is the principal source rock of oil and associated gas in Cook Inlet (Magoon and Anders, 1992; Magoon, 1994; Lillis and Stanley, 2011; LePain and others, 2012; LePain and others, submitted). During May 2009 helicopter-assisted field studies, 19 samples of dark-colored, fine-grained rocks were collected from exposures of the Red Glacier Formation of the Tuxedni Group near Red Glacier, about $70 \mathrm{~km}$ west of Ninilchik on the eastern flank of Iliamna Volcano (figs. 1 and 3). The rock samples were submitted to a commercial laboratory for analysis by Rock-Eval pyrolysis and to the U.S. Geological Survey organic geochemical laboratory in Denver, Colorado, for analysis of vitrinite reflectance. The results show that values of vitrinite reflectance (percent $R_{0}$ ) in our samples average about 2 percent, much higher than the oil window range of 0.6-1.3 percent (Johnsson and others, 1993). The high vitrinite reflectance values indicate that the rock samples experienced significant heating and furthermore suggest that these rocks may have generated oil and gas in the past but no longer have any hydrocarbon source potential. The high thermal maturity of the rock samples may have resulted from (1) the thermal

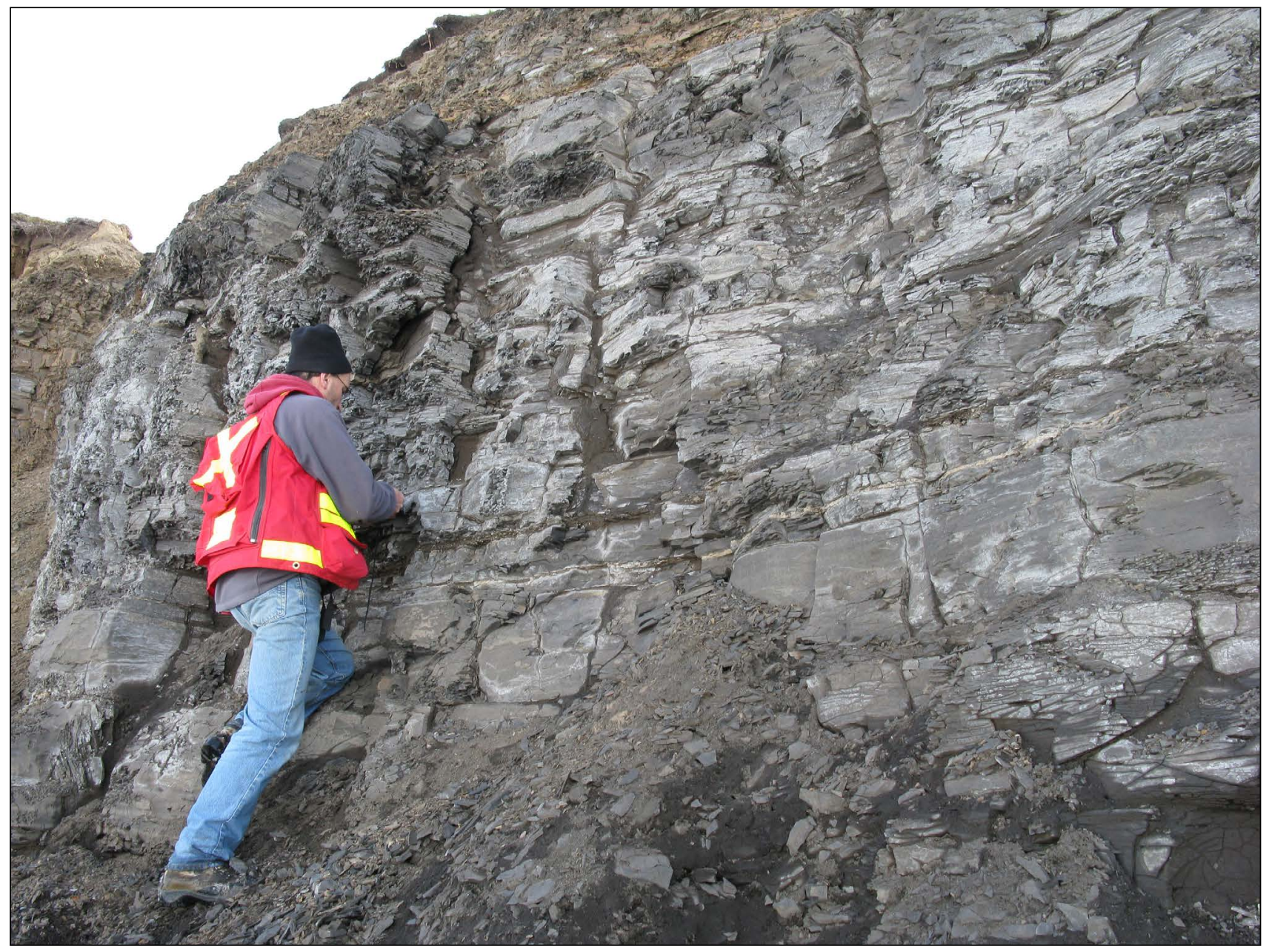

Figure 3. Outcrop of well stratified, dark-colored silty mudstone in the Middle Jurassic Red Glacier Formation of the Tuxedni Group. This outcrop is on the north side of Red Glacier, about $70 \mathrm{~km}$ west of Ninilchik on the west side of Cook Inlet. David LePain (DGGS) for scale. Photo by Rick Stanley (USGS), 2009. 
effects of igneous activity (including intrusion by igneous rocks), (2) deep burial beneath Jurassic, Cretaceous, and Tertiary strata that were subsequently removed by uplift and erosion, or (3) the combined effects of igneous activity and burial.

During helicopter-assisted field studies in July 2012, we briefly revisited outcrops of the Red Glacier Formation in the Red Glacier area and found numerous beds of sandstone (fig. 4) as well as several igneous dikes and sills (figs. 5-8) that were hidden by snow during our visit in 2009. In the initial aerial reconnaissance of our 2012 visit, it proved somewhat difficult to differentiate between the sandstone beds and sills because both lithologies are commonly very thick, with resistant weathering profiles and bedding perpendicular joint sets (fig. 8). In laterally persistent exposures, however, field relations serve to aid in clarifying which resistant beds are sills (fig. 8) versus sandstones (fig. 9). We found no evidence of extrusive volcanism (such as lava flows) in the Red Glacier Formation during this work and we directly observed hornfels facies in fine-grained strata immediately overlying the sill at locality 12TMH113 (see fig. 8), demonstrating that the sill is an intrusive rather than an extrusive igneous rock. The appreciable cumulative thickness of Red Glacier Formation-hosted sills north of Red Glacier (fig. 8) is noteworthy from a thermal perspective, and may shed additional light on the origin(s) of the high thermal maturity of the unit in this area. Rock samples from the dikes and sills were collected and will be submitted for isotopic age dating (see figs. 5-8); we anticipate that the results will help constrain the geologic history of the Red Glacier area and perhaps provide insights into the timing of oil generation and expulsion on the west side of Cook Inlet basin.

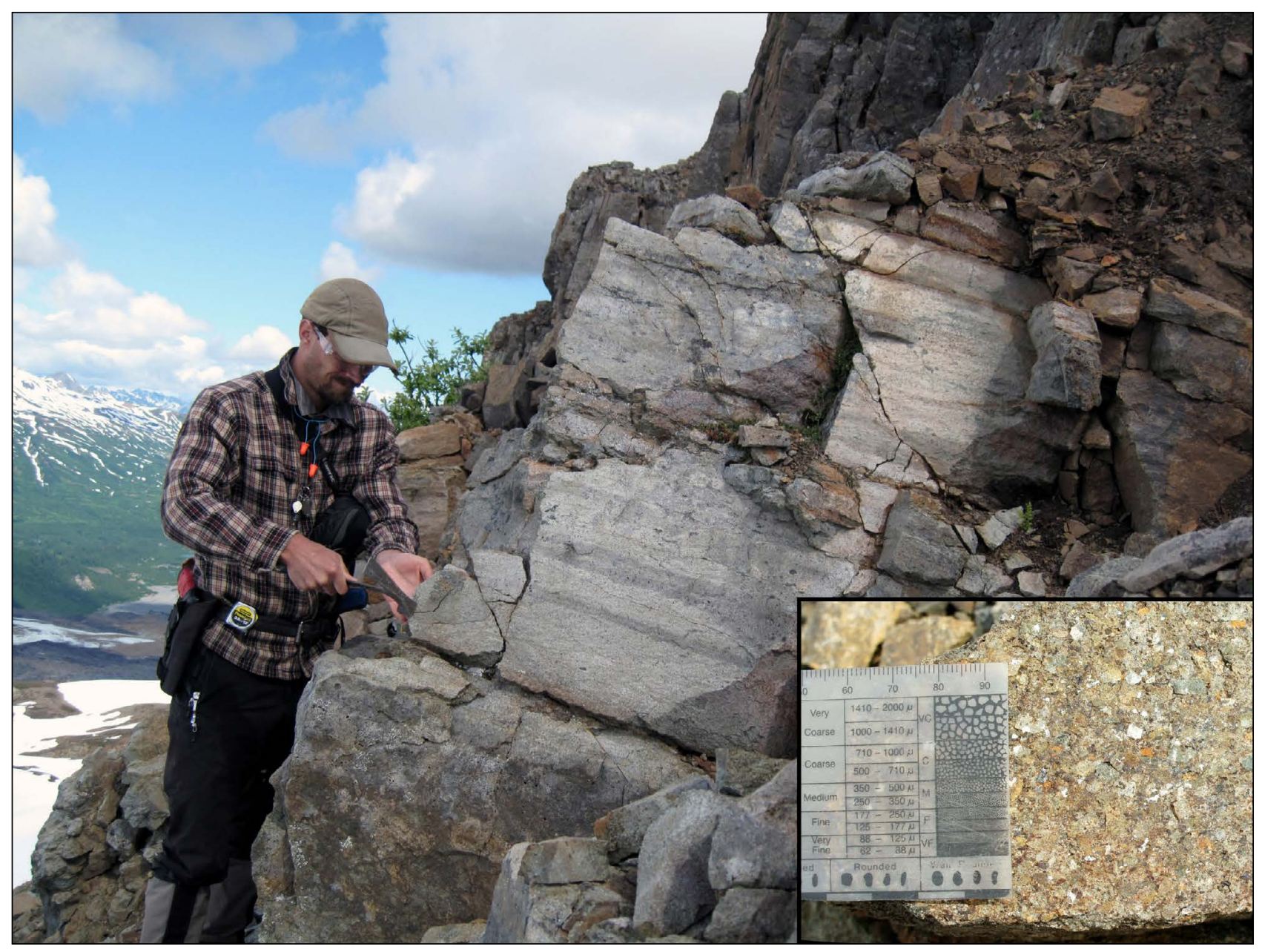

Figure 4. Outcrop of medium-gray-weathering, coarse sandstone (see inset photograph) in the Red Glacier Formation, north of Red Glacier. This sandstone is composed mainly of lithic volcanogenic particles derived from a volcanic edifice that was uplifted and eroded during the Middle Jurassic. A dark-gray-brown-weathering porphyritic sill immediately overlies the volcaniclastic sandstone (upper right). Trystan Herriott (DGGS) for scale. Photo by Rick Stanley (USGS), 2012. 


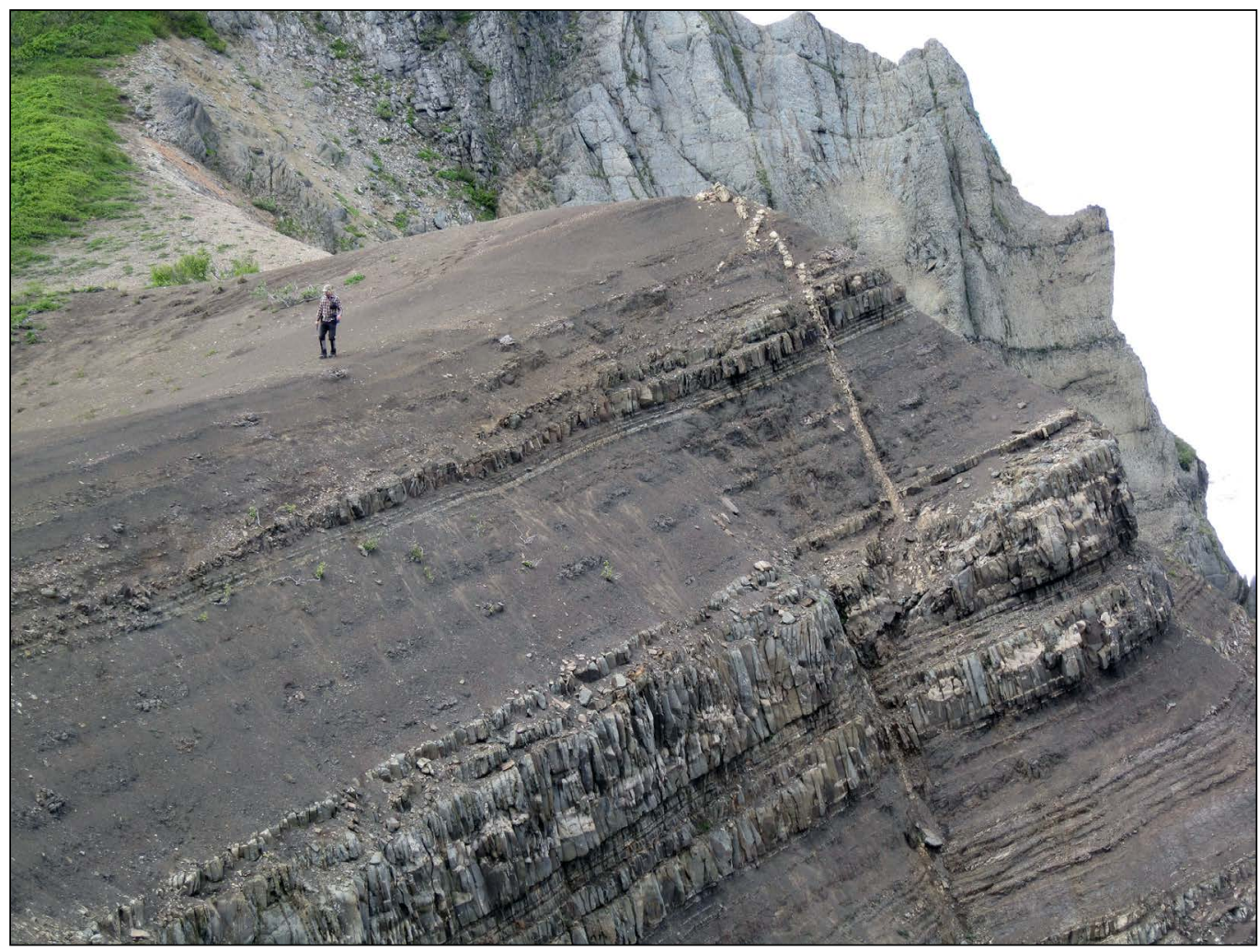

Figure 5. At right of photo, a prominent igneous dike crosscuts a well layered outcrop of Red Glacier Formation on the south side of Red Glacier. Trystan Herriott (DGGS) for scale. Photo by Rick Stanley (USGS), 2012.

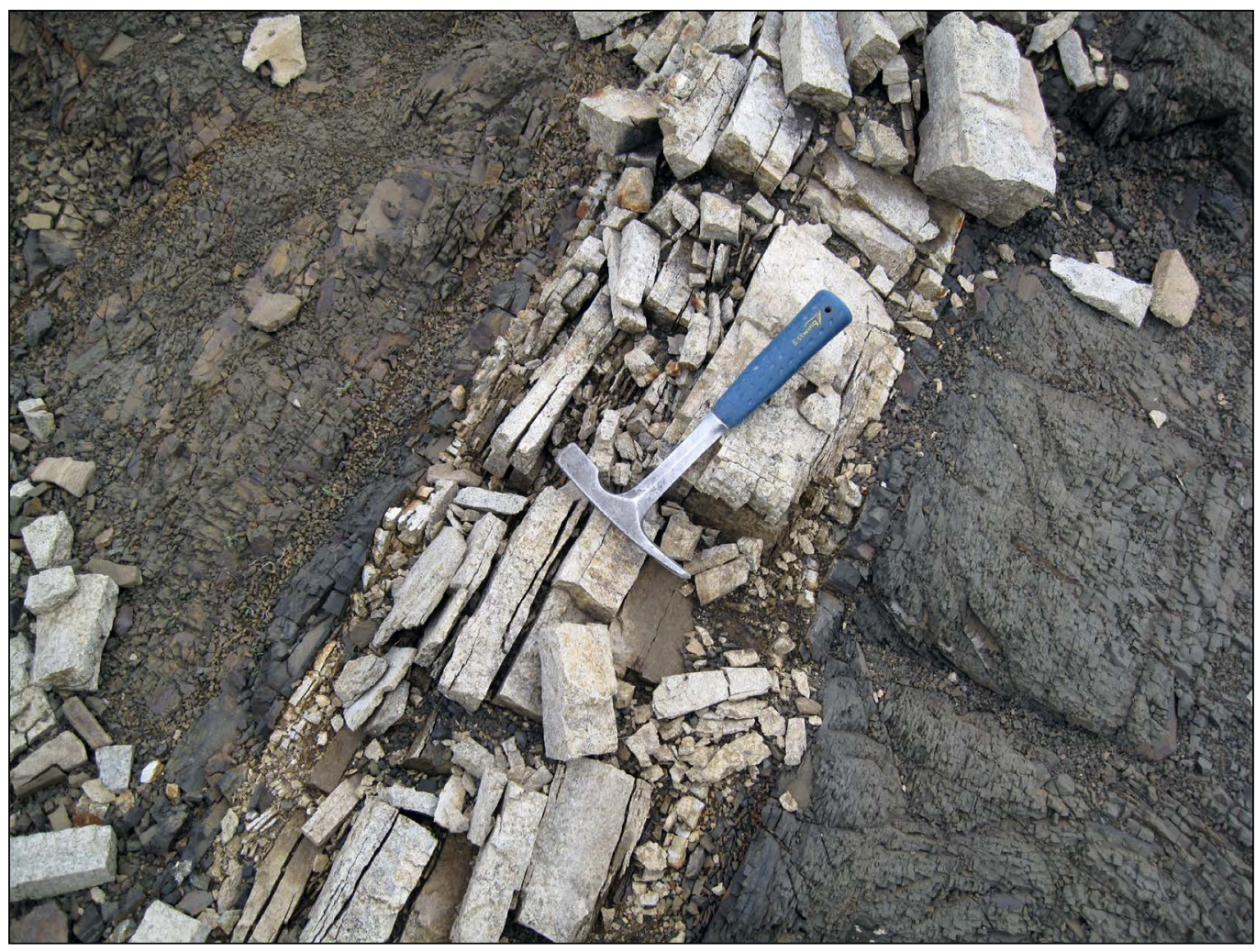

Figure 6. Detail of the light-colored, 35-cm-thick igneous dike in figure 5 that cross-cuts dark-colored silty mudstone of the Red Glacier Formation. We collected a rock sample from this dike for geochronologic analysis. Rock hammer is about $30 \mathrm{~cm}$ long. Photo by Rick Stanley (USGS), 2012. 


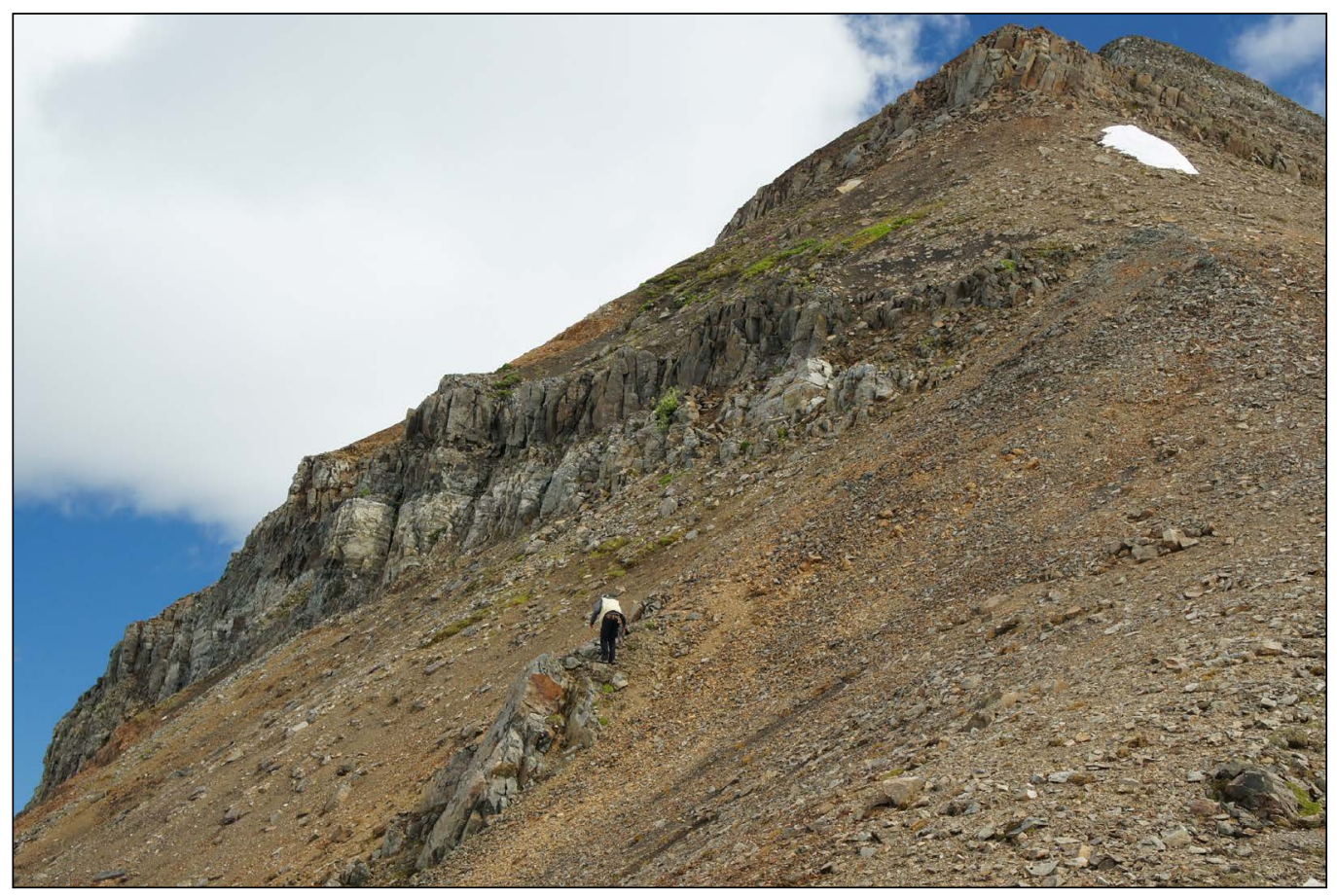

Figure 7. View toward the east of an exposure of the Red Glacier Formation north of Red Glacier. Medium-gray-weathering sandstone of figure 4 lies directly above photo centerline. A sample for geochronologic analysis was collected from the columnar jointed sill along right skyline of photo. Covered intervals largely comprise dark-gray-colored, fine-grained strata (siltstone and mudstone) that, where in close proximity to sills, are altered to hornfels. Rick Stanley (USGS) for scale. Photo by Trystan Herriott (DGGS), 2012.

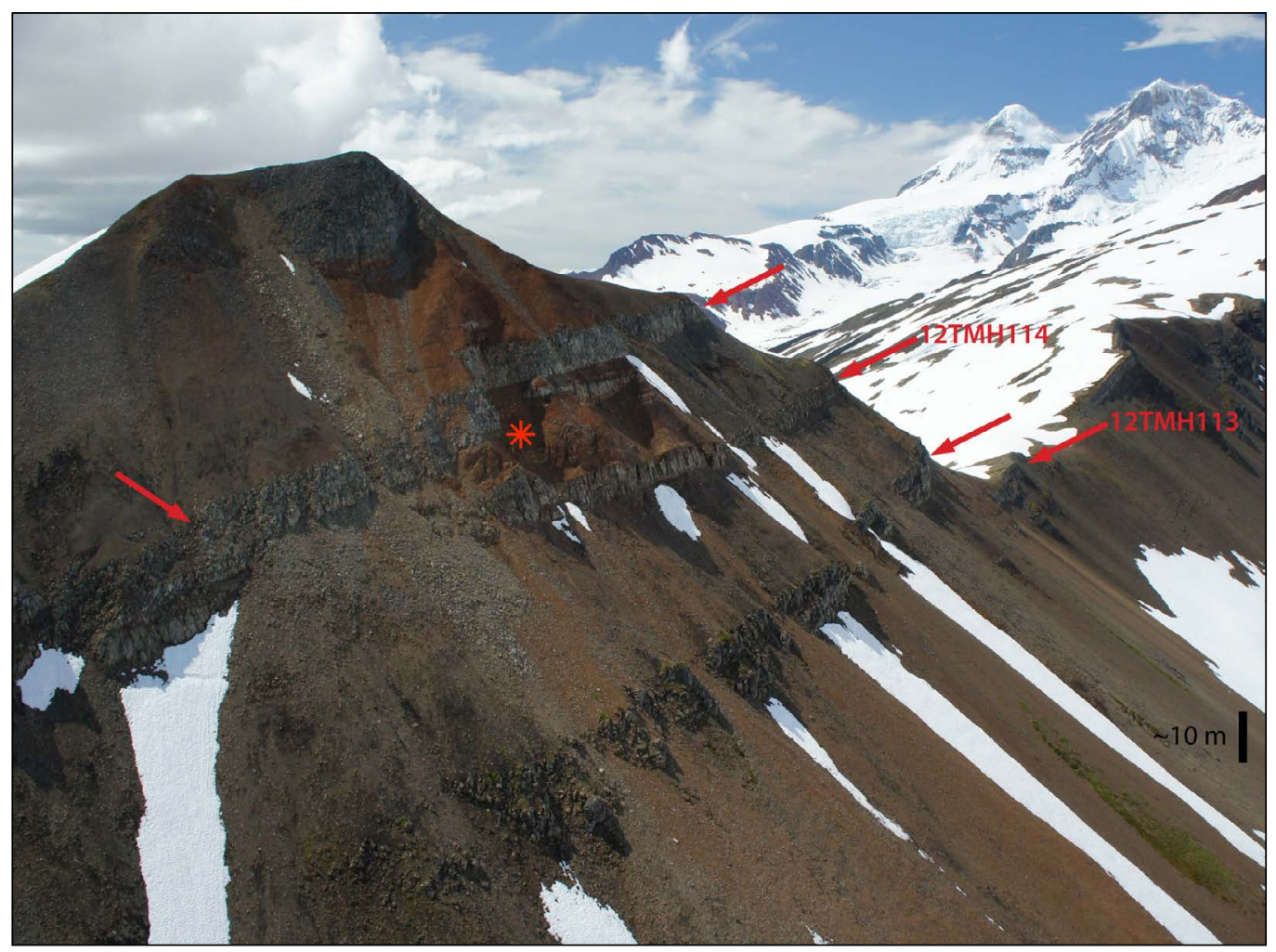

Figure 8. Oblique aerial view toward the southwest of Red Glacier Formation strata that crop out north of Red Glacier. The prominent, resistant weathering, jointed (bedding perpendicular), >5-m-thick, tabular igneous bodies marked by red arrows are porphyritic sills that are locally columnar jointed. Crosscutting relations near the red asterisk are poorly understood and may have resulted from faulting or irregularities in sill geometry during intrusion. The volcaniclastic sandstone of figure 4 lies stratigraphically directly below the sill between stations 12TMH113 and 12TMH114; at both stations, samples were collected from the sills and submitted for geochronologic analyses. 


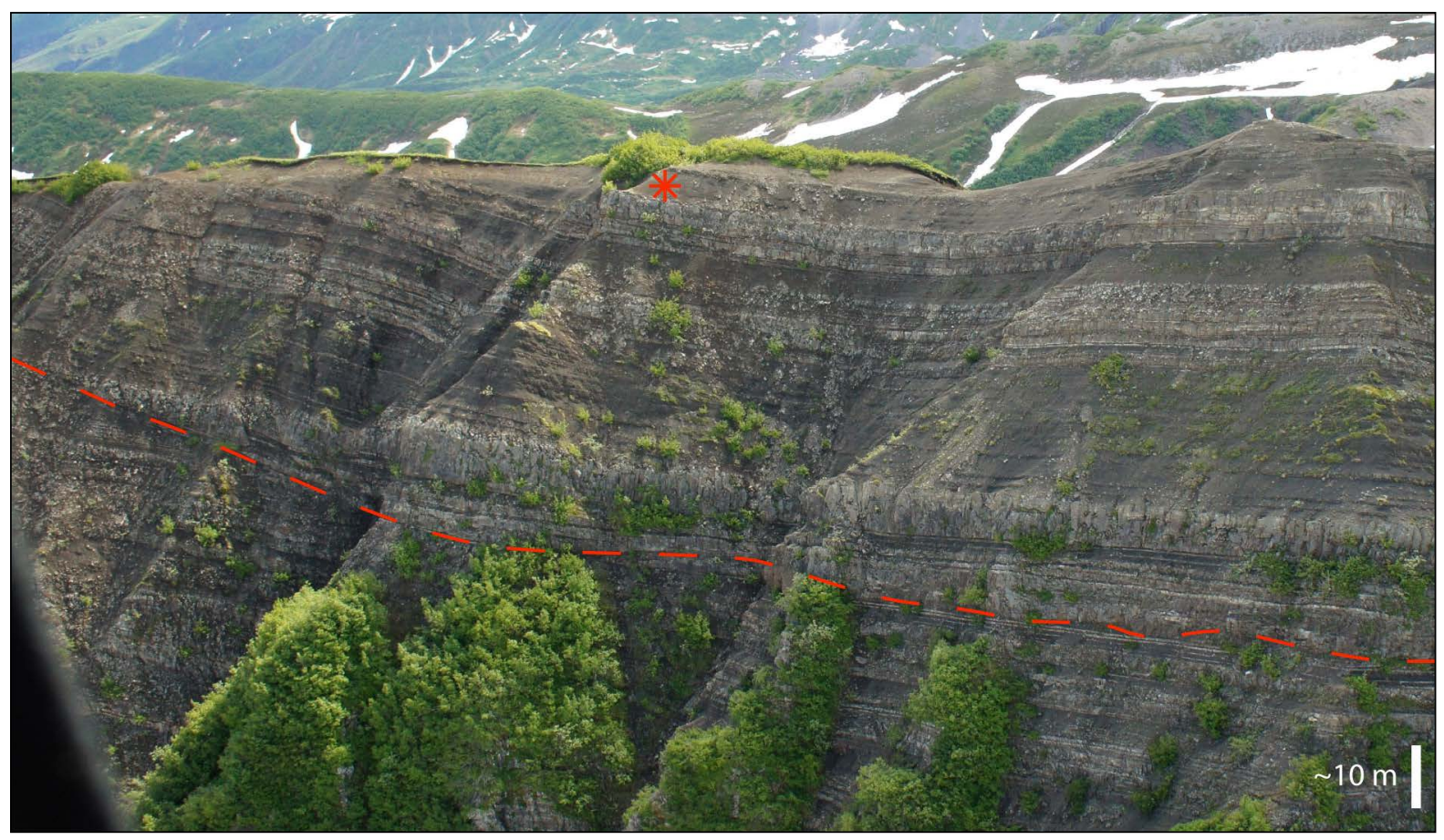

Figure 9. Oblique aerial view toward the southwest of Red Glacier Formation south of Red Glacier. Note that exposures beneath the red asterisk are unreachable because of precipitously steep slopes. The prominent, resistant weathering, jointed (bedding perpendicular), light-colored layer at photo centerline is likely an approximately 8-m-thick sandstone bed that seems to onlap the margins of a deep-water(?) channel (interpreted channel base shown by dashed red line). Sandstones and igneous sills are common in the Red Glacier Formation and have similar outcrop expression; therefore, care must be taken when trying to distinguish sandstones from sills in outcrops such as this that are inaccessible and must be viewed from a distance. 